\title{
Combination ergotamine and caffeine improves seated blood pressure and presyncopal symptoms in autonomic
} failure

\author{
Amy C. Arnold ${ }^{1}$, Claudia E. Ramirez ${ }^{1}$, Leena Choi ${ }^{2}$, Luis E. Okamoto ${ }^{1}$, Alfredo Gamboa ${ }^{1}$, \\ André Diedrich ${ }^{1}$, Satish R. Raj ${ }^{1}$, David Robertson ${ }^{1}$, Italo Biaggioni' ${ }^{1}$ and Cyndya A. Shibao ${ }^{1 *}$
}

${ }^{1}$ Division of Clinical Pharmacology, Department of Medicine, Autonomic Dysfunction Center, Vanderbilt University School of Medicine, Nashville, TN, USA

${ }^{2}$ Department of Biostatistics, Vanderbilt University School of Medicine, Nashville, TN, USA

\section{Edited by:}

Qi Fu, The Institute for Exercise and Environmental Medicine and UT

Southwestern Medical Center, USA

\section{Reviewed by:}

Yoshiki Kaneoke, Wakayama

Medical University, Japan

Alexander V. Ovechkin, University of

Louisville, USA

*Correspondence:

Cyndya A. Shibao, Division of Clinical Pharmacology, Department of Medicine, Autonomic Dysfunction Center, Vanderbilt University School of Medicine, 562 Preston Research Building, 2222 Pierce Avenue,

Nashville, TN 37232-6602, USA

e-mail:cyndya.shibao@

vanderbilt.edu
Severely affected patients with autonomic failure require pressor agents to counteract the blood pressure fall and improve presyncopal symptoms upon standing. Previous studies suggest that combination ergotamine and caffeine may be effective in the treatment of autonomic failure, but the efficacy of this drug has not been evaluated in controlled trials. Therefore, we compared the effects of ergotamine/caffeine on seated blood pressure and orthostatic tolerance and symptoms in 12 primary autonomic failure patients without history of coronary artery disease. Patients were randomized to receive a single oral dose of placebo, midodrine (5-10 mg), or ergotamine and caffeine ( 1 and $100 \mathrm{mg}$, respectively) in a single-blind, crossover study. Blood pressure was measured while patients were seated and after standing for up to $10 \mathrm{~min}$, at baseline and at $1 \mathrm{~h}$ post-drug. Ergotamine/caffeine increased seated systolic blood pressure (SBP), the primary outcome, compared with placebo $(131 \pm 19$ and $95 \pm 12 \mathrm{mmHg}$, respectively, at $1 \mathrm{~h}$ post-drug; $p=0.003$ for time effect). Midodrine also significantly increased seated SBP $(121 \pm 19 \mathrm{mmHg}$ at $1 \mathrm{~h}$ post-drug; $p=0.015$ for time effect vs. placebo), but this effect was not different from ergotamine/caffeine $(p=0.621)$. There was no significant effect of either medication on orthostatic tolerance; however, ergotamine/caffeine improved presyncopal symptoms $(p=0.034)$. These findings suggest that combination ergotamine and caffeine elicits a seated pressor response that is similar in magnitude to midodrine, and improves symptoms in autonomic failure. Thus, ergotamine/caffeine could be used as an alternate treatment for autonomic failure, in carefully selected patients without comorbid coronary artery disease.

Keywords: autonomic failure, orthostatic hypotension, ergotamine, caffeine, pressor agent

\section{INTRODUCTION}

The autonomic nervous system maintains blood pressure during standing (Smith et al., 1994; Diedrich and Biaggioni, 2004). A failure of this system, as in autonomic failure, results in orthostatic hypotension. Severely affected patients with autonomic failure can only stand for a few seconds to minutes before developing disabling presyncopal symptoms and even syncope, and often exhibit low blood pressure even in the seated position. Although non-pharmacologic measures such as physical counter-maneuvers are the first step in treatment of autonomic failure, pressor agents are often needed in severe patients to adequately control symptoms (Arnold and Shibao, 2013). Currently, there are only two drugs approved for treatment of orthostatic hypotension, the $\alpha_{1}$-adrenergic agonist midodrine and the norepinephrine prodrug droxidopa. The use of these drugs can be limited by adverse effects, however, and the FDA recently proposed the withdrawal of midodrine due to lack of post-marketing evidence to support its clinical efficacy (Dhruva and Redberg, 2010). Thus, there is an emerging need to identify additional therapeutic options for patients with autonomic failure.

Previous small studies, ranging from 1 to 10 patients, have shown that the $\alpha$-adrenergic agonist ergotamine increases standing blood pressure and improves symptoms in patients with orthostatic hypotension when given by inhaled, intramuscular, or oral routes of administration (Bevegard et al., 1974; Benowitz et al., 1980; Fouad et al., 1981; Chobanian et al., 1983; Hoeldtke et al., 1986; Biaggioni et al., 1990). Oral administration of ergotamine combined with caffeine, to improve its effectiveness and absorption (Schmidt and Fanchamps, 1974), also improved standing blood pressure and presyncopal symptoms in a study of eight autonomic failure patients with parkinsonism and refractory orthostatic hypotension (Dewey et al., 1998). In this previous study, however, patients were administered ergotamine/caffeine in an open-label and uncontrolled fashion. Therefore, the aim of this study was to systematically evaluate the effect of ergotamine/caffeine, compared with placebo and the standard of care midodrine, on seated blood pressure and orthostatic 
tolerance and symptoms in patients with severe autonomic failure.

\section{MATERIALS AND METHODS AUTONOMIC FAILURE PATIENTS}

A total of 12 primary autonomic failure patients were recruited from referrals to the Vanderbilt Autonomic Dysfunction Center. Patients had a documented history of neurogenic orthostatic hypotension, defined as $\geq 20 \mathrm{mmHg}$ decrease in systolic blood pressure (SBP) and/or $\geq 10 \mathrm{mmHg}$ decrease in diastolic blood pressure (DBP) within 3 min of standing (Freeman et al., 2011), and severe autonomic impairment. The consensus criteria from the American Autonomic Society were used to ascertain the diagnosis of autonomic failure (Freeman et al., 2011). Eight patients were diagnosed with pure autonomic failure (PAF), a primary neurodegenerative disorder characterized by postganglionic autonomic denervation and neurogenic orthostatic hypotension, 2 patients with Parkinson's disease $(\mathrm{PD}+)$ and 2 with multiple systems atrophy of parkinsonian type (MSAP). Patients were excluded if they had secondary causes of autonomic failure (e.g., diabetes mellitus, amyloidosis, autoimmune autonomic ganglionopathy) or had current or history of coronary artery disease. All procedures were approved by the Vanderbilt Institutional Review Board and patients provided written informed consent. This study was registered at ClinicalTrials.gov under "Treatment of Orthostatic Hypotension in Autonomic Failure" (NCT00223691).

\section{GENERAL PROTOCOL}

Patients were admitted to the Vanderbilt General Clinical Research Center, and placed on a low-monoamine, caffeine-free, diet containing $150 \mathrm{mEq}$ sodium and $60-80 \mathrm{mEq}$ potassium per day, for at least 3 days before evaluation. All patients underwent a comprehensive medical history and physical examination. Medications affecting the autonomic nervous system and blood volume (such as fludrocortisone) were withheld for at least five half-lives before admission. Both $\mathrm{PD}+$ patients, however, remained on carbidopa/levodopa (sinemet) for the duration of their inpatient stay due to safety concerns. All patients were evaluated with standardized autonomic function tests (e.g., orthostatic stress, sinus arrhythmia, Valsalva maneuver, hyperventilation, cold pressor, and isometric handgrip tests) (Low, 2003; Okamoto et al., 2012). Orthostatic stress testing was consistently performed starting at $8 \mathrm{a} . \mathrm{m}$. to avoid circadian differences in hemodynamic and biochemical measures. Blood pressure and heart rate were measured after patients were supine for at least $30 \mathrm{~min}$ and again after $1,3,5$, and $10 \mathrm{~min}$ of standing, or as long as tolerated, using an automated brachial sphygmomanometer cuff (Dinamap ProCare 100, GE Healthcare). Supine and standing blood samples were collected from an antecubital vein catheter, placed at least 30 min before testing, for measurement of plasma norepinephrine by HPLC with electrochemical detection (Goldstein et al., 1988).

\section{ACUTE MEDICATION TRIALS}

Autonomic failure patients participated in a crossover study with oral placebo, 5 or $10 \mathrm{mg}$ midodrine (Shire PLC) and combination $1 \mathrm{mg}$ ergotamine and $100 \mathrm{mg}$ caffeine (Cafergot, Novartis
Pharmaceuticals) administered on separate days. The doses of midodrine and ergotamine/caffeine have been previously shown to elicit pressor responses in autonomic failure patients (Low et al., 1997; Dewey et al., 1998; Wright et al., 1998). Patients were administered the dose of midodrine that they were prescribed to regularly take at home, reflecting standard of care. There were four patients that received the $5 \mathrm{mg}$ dose (2 PAF, 2 MSA) and eight patients that received the $10 \mathrm{mg}$ dose ( $6 \mathrm{PAF}, 2 \mathrm{PD}+$ ). The order of medications was randomized using computer generated random numbers, and was blinded to patients (single-blind).

Acute medication trials were conducted at least $2 \mathrm{~h}$ after meals to avoid post-prandial hemodynamic effects, and in post-void state. Patients were seated in a chair with their feet on the floor, consistent with our previous trials of pressor agents in autonomic failure (Jordan et al., 1998; Shibao et al., 2010; Okamoto et al., 2012). Blood pressure was measured using an automated brachial sphygmomanometer cuff placed on the right arm, and heart rate by continuous ECG (Dinamap). Data were digitally acquired into a custom database (Microsoft Access, Microsoft Corporation). During baseline, seated blood pressure and heart rate were measured every $5 \mathrm{~min}$ for $30 \mathrm{~min}$. Orthostatic tolerance was assessed by measuring blood pressure and heart rate after 1, 3, 5, and $10 \mathrm{~min}$ of standing, or as long as tolerated. Patients were then asked to sit and were given the study medication with $50 \mathrm{ml}$ tap water. Seated blood pressure and heart rate were measured every $5 \mathrm{~min}$ for $60 \mathrm{~min}$ after drug administration, with orthostatic tolerance assessed at the end of this period. We assessed blood pressure at $60 \mathrm{~min}$ post-drug as it corresponds to the peak effect of midodrine on standing blood pressure in autonomic failure (Wright et al., 1998), and the time for peak plasma levels of ergotamine (Silberstein and McCrory, 2003). Ergotamine has been shown, however, to improve orthostatic hypotension and symptoms up to $2 \mathrm{~h}$ after oral or inhaled administration in autonomic failure (Biaggioni et al., 1990; Dewey et al., 1998). Patients were asked to self-rate the severity of presyncopal symptoms at the end of baseline and post-drug standing periods using a validated orthostatic symptom score (Kaufmann et al., 2012). This score comprises 6 symptoms: (1) dizziness, light-headedness, feeling faint or feeling like you might black out; (2) problems with vision (blurring, seeing spots, tunnel vision); (3) generalized weakness; (4) fatigue; (5) trouble concentrating; and (6) head/neck discomfort. These symptoms are rated individually in terms of severity on a scale of 0 to 10 , with 0 reflecting absence of symptoms. Changes in composite symptom scores from baseline to $60 \mathrm{~min}$ post-drug were compared for each medication. In addition, changes in scores from Question 1 (lightheadedness), the symptom most commonly described by patients with orthostatic hypotension (Kaufmann et al., 2012; Shibao et al., 2012), were compared for each medication from baseline to $60 \mathrm{~min}$ post-drug. All procedures were performed by trained research nurses and in accordance with institutional guidelines.

\section{STATISTICAL ANALYSIS}

We tested the null hypothesis that there is no difference in seated blood pressure following placebo, midodrine, and ergotamine/caffeine administration in autonomic failure. The 
primary outcome was defined a priori as the seated SBP during the 60-min post-drug period, with adjustment for average seated SBP at baseline. Baseline and post-drug seated SBP values were logarithmic transformed to reduce skewness in their distribution. A random effects model with random intercept and random slope for time was used to examine for differences in the mean log seated SBP during the 60 -min post-drug period among treatment groups. The following terms were included in the model: treatment group, time, time and treatment interaction, and average seated SBP at baseline. Differences in baseline seated SBP among study days were compared with Friedman non-parametric tests. Differences in the seated pressor response between midodrine and ergotamine/caffeine were compared using a McNemar non-parametric test. Secondary outcomes included orthostatic tolerance and presyncopal symptoms measured by the orthostatic symptoms score. Orthostatic tolerance was defined as area under the curve for standing SBP calculated by the trapezoidal rule (AUC $\mathrm{SBP}_{\mathrm{S}}$ : upright SBP multiplied by standing time). The difference in the $\mathrm{AUC}_{\mathrm{SBP}}$ between baseline and post-drug $\left(\triangle \mathrm{AUC}_{\mathrm{SBP}}\right)$ was used to test whether orthostatic tolerance differed among treatment groups using a random effects model. Comparisons were made only for patients who could stand after all active medications. Differences in orthostatic symptom scores from baseline to 60 min post-administration were compared within each individual drug using Wilcoxon signed-rank non-parametric tests. Data are presented as mean $\pm 95 \%$ confidence interval (CI) unless otherwise specified. All tests were two-tailed, and a $p$-value $<0.05$ was considered significant. Analyses were performed with SPSS (version 22.0, IBM Corporation, Chicago, IL) and STATA (version 12.0, StataCorp, College Station, TX).

Sample size calculations were performed using paired $t$-test analysis in PS software (Version 3.0.34) (Dupont and Plummer, 1990). A blinded analysis was performed on preliminary data obtained from the first 3 patients enrolled in this study to obtain an estimate of variance, and showed an approximate $17 \mathrm{mmHg}$ standard deviation of difference in seated SBP among treatment groups. An increase in seated blood pressure of $20 \mathrm{mmHg}$ would be a clinically meaningful difference, representing the approximate magnitude of response achieved with other vasoconstrictor drugs (Jordan et al., 1998). Based on these data, we estimated that 10 patients would have $90 \%$ power to detect a difference in means among treatment groups. Since sample size calculations were performed using parametric tests, we increased the sample size by $15 \%$ to account for analysis of outcomes with non-parametric methods. Thus, 12 patients were included in this study.

\section{RESULTS}

\section{RESTING CARDIOVASCULAR AUTONOMIC FUNCTION}

Patient clinical characteristics are shown in Table 1. During screening, two patients (1 PAF, $1 \mathrm{PD}+$ ) were unable to stand for 1 min during the orthostatic stress testing due to presyncopal symptoms (Table 2 ). The remaining 10 patients exhibited profound decreases in SBP and DBP after 1 min of standing, without an adequate compensatory increase in heart rate. Autonomic failure patients had severe sympathetic and parasympathetic impairment compared with healthy subjects as indicated in Table 3
Table 1 | Patient clinical characteristics.

\begin{tabular}{lccccc}
\hline Patient & Diagnosis & Sex & $\begin{array}{c}\text { BMI } \\
\left(\mathbf{k g} / \mathbf{m}^{\mathbf{2}}\right)\end{array}$ & $\begin{array}{c}\text { Age } \\
\text { (years) }\end{array}$ & $\begin{array}{c}\text { Disease duration } \\
\text { (years) }\end{array}$ \\
\hline 1 & PAF & M & 25 & 83 & 7 \\
2 & PAF & M & 30 & 47 & 6 \\
3 & PAF & M & 34 & 65 & 2 \\
4 & PAF & M & 29 & 70 & 2 \\
5 & PD+ & F & 20 & 71 & 10 \\
6 & PAF & F & 23 & 70 & 2 \\
7 & MSA-P & M & 33 & 57 & 2 \\
8 & PAF & M & 25 & 69 & 8 \\
9 & PAF & F & 26 & 65 & 10 \\
10 & PAF & M & 30 & 65 & 6 \\
11 & PD+ & F & 22 & 56 & 7 \\
12 & MSA-P & M & 32 & 52 & 4 \\
\hline
\end{tabular}

BMI, body mass index; PAF, pure autonomic failure; $P D+$, Parkinson's disease with autonomic failure; MSA-P, multiple systems atrophy with parkinsonian features.

Table 2 | Orthostatic stress testing.

\begin{tabular}{|c|c|c|c|c|c|c|}
\hline \multirow[t]{2}{*}{ Patient } & \multicolumn{2}{|c|}{$\begin{array}{l}\text { Blood pressure } \\
\text { (mmHg) }\end{array}$} & \multicolumn{2}{|c|}{$\begin{array}{l}\text { Heart rate } \\
\text { (bpm) }\end{array}$} & \multicolumn{2}{|c|}{$\begin{array}{c}\text { Plasma NE } \\
(\mathrm{pg} / \mathrm{ml})\end{array}$} \\
\hline & Supine & Upright & Supine & Upright & Supine & Upright \\
\hline 1 & $182 / 85$ & $114 / 62$ & 61 & 68 & 106 & 200 \\
\hline 2 & $148 / 100$ & $70 / 45$ & 71 & 81 & 38 & 67 \\
\hline 3 & $111 / 59$ & $66 / 46$ & 74 & 111 & 117 & 140 \\
\hline 4 & 139/87 & $65 / 47$ & 62 & 86 & 25 & 84 \\
\hline 5 & $139 / 74$ & $88 / 47$ & 78 & 98 & 55 & 44 \\
\hline 6 & 159/69 & $66 / 40$ & 74 & 103 & 219 & 306 \\
\hline 7 & 119/77 & $83 / 61$ & 69 & 81 & 251 & 540 \\
\hline 8 & $112 / 65$ & $66 / 41$ & 69 & 75 & 30 & 22 \\
\hline 9 & $95 / 64$ & $--/--$ & 93 & -- & 378 & -- \\
\hline 10 & $127 / 83$ & $95 / 61$ & 70 & 82 & 122 & 303 \\
\hline 11 & $86 / 64$ & $--/-$ & 77 & -- & 274 & -- \\
\hline 12 & 136/87 & $94 / 58$ & 85 & 85 & 135 & 184 \\
\hline
\end{tabular}

Hemodynamic measurements and blood samples were obtained while patients were supine (at least $30 \mathrm{~min}$ ) and upright (after 1 min of standing). Blood pressure values represent systolic/diastolic. NE, norepinephrine; - -, patient was not able to stand for 1 min to obtain hemodynamic measurements and blood samples due to presyncopal symptoms.

by: (a) reduced sinus arrhythmia ratio; (b) reduced Valsalva maneuver heart rate ratio; (c) exaggerated depressor response during phase II and absence of blood pressure overshoot during phase IV of the Valsalva maneuver; and (d) impaired pressor responses to isometric handgrip exercise or pain stimulus (cold pressor test).

\section{PRESSOR RESPONSE TO DRUGS}

The average seated SBP during the 30-min baseline period was similar among placebo, ergotamine/caffeine, and midodrine study days ( $p=0.441$; Friedman test). Ergotamine/caffeine 
Table 3 | Autonomic function tests.

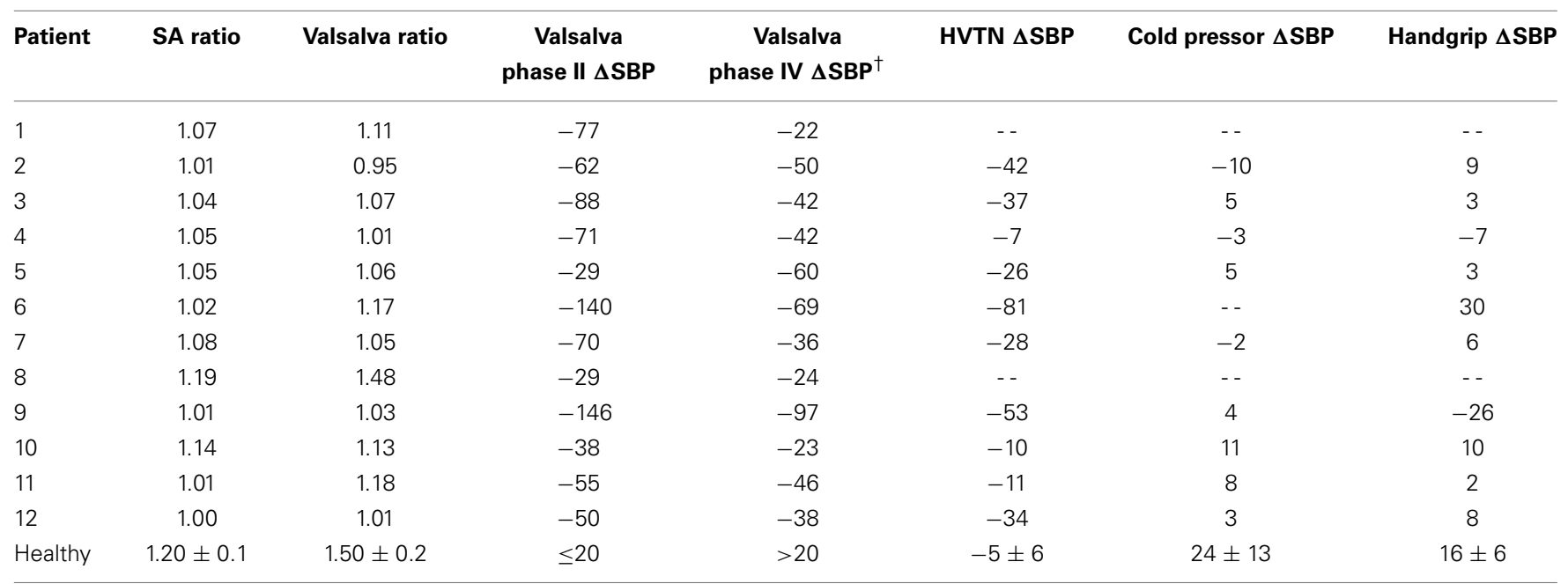

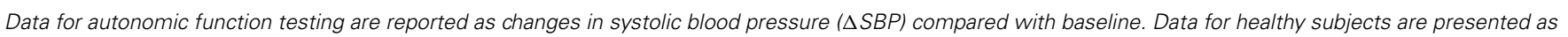

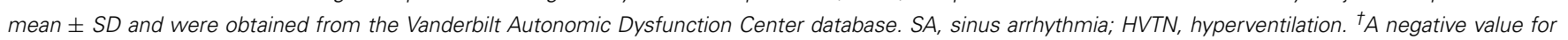
phase IV of the Valsalva maneuver indicates that the blood pressure overshoot was absent. --, patient was not able to tolerate test.

significantly increased seated SBP, the primary outcome, as a linear function of time compared with placebo (Figure 1; slope difference: 1.003 ; $95 \%$ CI: 1.001 to $1.005 ; p=0.003$; random effects model). Similarly, midodrine increased seated SBP compared with placebo (Figure 1; slope difference: 1.002; 95\% CI: $1.001-1.004 ; p=0.015$; random effects model). The magnitude of the seated pressor response to midodrine was similar between patients receiving the $5 \mathrm{mg}$ (median: 26; IQR: 14-36) and $10 \mathrm{mg}$ (median: 23; IQR: 7-48) doses. There was no significant difference, however, in the seated pressor response between ergotamine/caffeine and midodrine (slope difference: 1.000; 95\% CI: $0.998-1.001 ; p=0.621$; random effects model). In this study, 9 out of $12(75 \%)$ patients exhibited an increase in seated SBP $\geq$ $20 \mathrm{mmHg}$ with ergotamine/caffeine compared with 5 out of 12 (42\%) patients for midodrine, a difference that was not significantly different ( $p=0.125$; McNemar test).

\section{ORTHOSTATIC TOLERANCE AND SYMPTOMS}

As shown in Figure 2, at $60 \mathrm{~min}$ after placebo administration 5 out of $12(42 \%)$ autonomic failure patients could stand for $10 \mathrm{~min}$, compared with 8 out of $12(67 \%)$ after ergotamine/caffeine and 6 out of $12(50 \%)$ after midodrine. There was no significant difference, however, in orthostatic tolerance between ergotamine/caffeine and placebo $\left(\triangle \mathrm{AUC}_{\mathrm{SBP}}\right.$ : 248 ; $95 \%$ CI: -73 to $568 ; p=0.130$; random effects model), between midodrine and placebo $\left(\triangle \mathrm{AUC}_{\mathrm{SBP}}: 85 ; 95 \% \mathrm{CI}:-141\right.$ to $311 ; p=0.461)$, or between ergotamine/caffeine and midodrine ( $\triangle \mathrm{AUC}_{\mathrm{SBP}}:-163 ; 95 \% \mathrm{CI}:-387$ to $62 ; p=0.155$ ). The orthostatic symptom composite score, as well as the lightheadedness component of this score (Question 1), were reduced at $60 \mathrm{~min}$ following ergotamine/caffeine administration (Figure 3; $p=0.034$ and 0.040 , respectively; Wilcoxon signed-rank test) when compared with baseline. In contrast, there was no significant effect of either midodrine or placebo on orthostatic symptom scores (Figure 3).

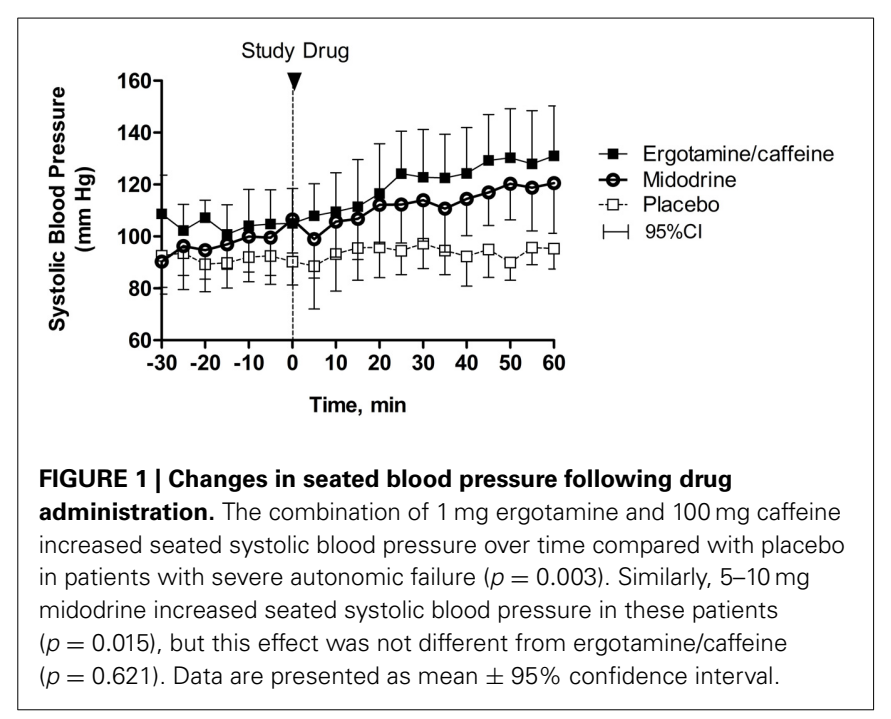

\section{DISCUSSION}

The main finding of this study is that combination ergotamine and caffeine improves seated blood pressure in patients with severe autonomic failure, to a similar extent as the standard of care pressor agent midodrine. Furthermore, while there was no significant effect of either drug on orthostatic tolerance, ergotamine/caffeine improved presyncopal symptoms upon standing. These findings suggest that the combination of ergotamine and caffeine may be useful for the treatment of autonomic failure, particularly in patients without underlying vascular disease and who are unable to tolerate midodrine.

Autonomic failure is associated with sympathetic denervation and impaired baroreflex-mediated arteriolar vasoconstriction, leading to excessive venous pooling and reduced venous return to the heart upon assumption of the upright position. The peripheral $\alpha_{1}$-adrenergic agonist midodrine increases systemic vascular 

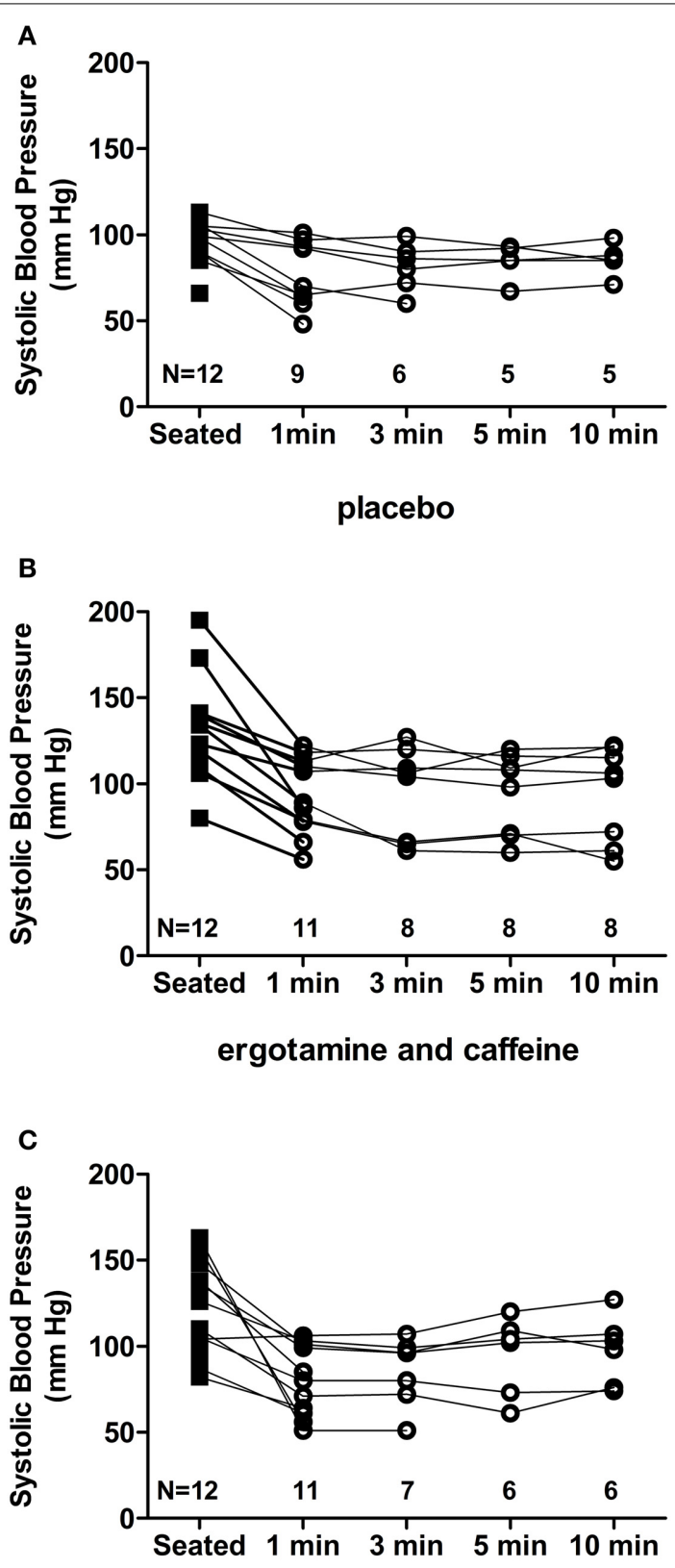

midodrine

FIGURE 2 | Orthostatic tolerance following drug administration. At $60 \mathrm{~min}$ following drug administration, autonomic failure patients were asked to stand for $10 \mathrm{~min}$, or as long as tolerated. Systolic blood pressure was measured at 1, 3, 5, and 10 min to assess orthostatic tolerance. Blood pressure data and standing time are shown for each individual patient, with $N$ representing the number of patients who could tolerate standing at a given time point. Five out of $12(42 \%)$ patients could stand for $10 \mathrm{~min}$ following placebo (A) compared with 8 out of $12(67 \%)$ after ergotamine/ caffeine (B) and 6 out of $12(50 \%)$ after midodrine (C) administration.

resistance, and has demonstrated efficacy to elevate blood pressure and improve presyncopal symptoms in autonomic failure (Schirger et al., 1981; Kaufmann et al., 1988; Jankovic et al., 1993; Fouad-Tarazi et al., 1995; Low et al., 1997; Wright et al.,

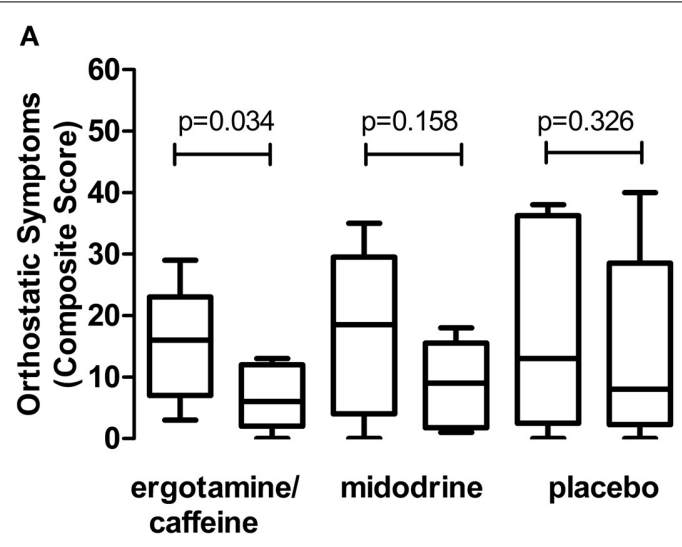

B

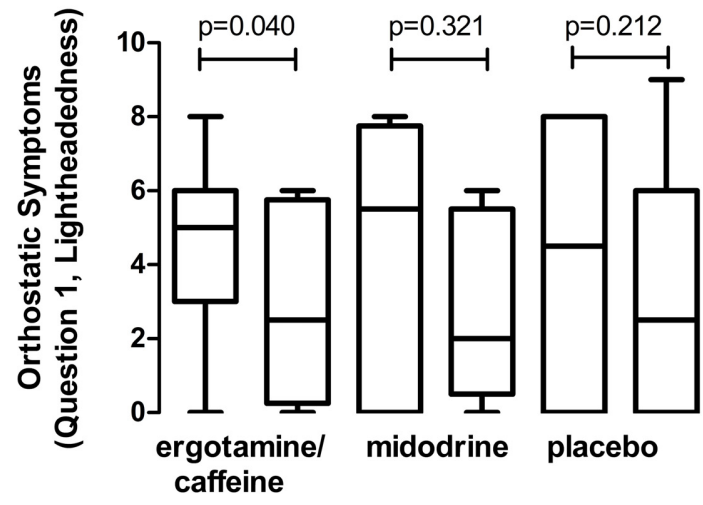

FIGURE 3 | Effect of drugs on orthostatic presyncopal symptoms. Data represent changes in orthostatic symptom scores from baseline (left bar) to 60 min post-administration (right bar), with comparisons made for each individual drug. (A) Combination $1 \mathrm{mg}$ ergotamine and $100 \mathrm{mg}$ caffeine reduced the orthostatic symptom composite score in autonomic failure patients, suggesting an improvement in presyncopal symptom burden. In contrast, there was no effect of 5-10 mg midodrine or placebo on this composite score. (B) Combination ergotamine and caffeine also reduced the lightheadedness component (Question 1) of the orthostatic symptoms score in these patients, with no significant effect of midodrine or placebo. Data are presented as mean $\pm 95 \%$ confidence interval.

1998). The increase in seated SBP with midodrine was similar in magnitude to a previous report in seated patients (Jordan et al., 1998), and to the effects of chronic administration on standing blood pressure (Jankovic et al., 1993). The use of midodrine is limited in some patients by adverse effects such as pilomotor reactions, pruritus of the scalp, urinary urgency or retention, and supine hypertension (Fouad-Tarazi et al., 1995; Low et al., 1997). We also recently reported poor persistence on treatment with midodrine in patients with neurogenic orthostatic hypotension (Shibao et al., 2013a). Furthermore, not all patients respond to midodrine, with a previous report showing a pressor effect in $69 \%$ and $38 \%$ of PD+ and MSA patients, respectively (Jankovic et al., 1993). Similarly, in this study only $42 \%$ of autonomic failure patients had a significant pressor response to midodrine. These findings illustrate the need to identify additional therapeutic options for the treatment of autonomic failure. 
In addition to potent vasoconstriction, ergotamine elicits peripheral venoconstriction through stimulation of $\alpha$ adrenoreceptors (Fouad et al., 1981; Chobanian et al., 1983). Ergotamine/caffeine could be more effective than midodrine in this regard by improving venous return, but this was not observed. There was a high response rate to ergotamine/caffeine with $75 \%$ of patients in this study and $100 \%$ of patients in a previous study (Dewey et al., 1998) exhibiting a greater than $20 \mathrm{mmHg}$ increase in seated and standing blood pressure, respectively. Some long-term benefit of ergotamine/caffeine to reduce presyncopal symptoms and syncopal episodes has also been demonstrated in small, uncontrolled studies (Chobanian et al., 1983; Dewey et al., 1998). It is difficult to predict which patients will respond to ergotamine/caffeine, however, as an acute test dose did not predict long-term efficacy in autonomic failure (Dewey et al., 1998). Furthermore, the severity of autonomic failure, results of autonomic function testing, and plasma catecholamine levels were shown to be poor predictors of response to pressor agents (Jordan et al., 1998). The magnitude of pressor responses to midodrine and ergotamine/caffeine (26 and $36 \mathrm{mmHg}$, respectively) likely reflects loss of baroreflex buffering, but may also involve enhanced adrenergic sensitivity. It is unlikely that caffeine played a major role in the seated pressor effect of ergotamine/caffeine treatment, as acute caffeine produces a modest pressor or no effect in autonomic failure (Onrot et al., 1985; Jordan et al., 1998).

The goal for treatment of autonomic failure is to reduce presyncopal symptoms and improve standing time, and not to treat underlying disease. This can be achieved by increasing seated blood pressure within the range of cerebral autoregulation, so that cerebral perfusion is maintained even with a fall in blood pressure during standing. In this study, orthostatic tolerance was defined as the AUC for standing SBP, to take into account not only blood pressure levels but also total standing time, similar to our previous studies (Shibao et al., 2010; Okamoto et al., 2012). Midodrine and ergotamine have both been shown to improve standing time and presyncopal symptoms in autonomic failure (Chobanian et al., 1983; Kaufmann et al., 1988; Biaggioni et al., 1990; Jankovic et al., 1993; Fouad-Tarazi et al., 1995; Low et al., 1997; Dewey et al., 1998; Wright et al., 1998), perhaps suggesting that this study was underpowered to detect differences in measures of orthostatic tolerance.

In this study, five patients were discharged on ergotamine/caffeine, of which three continued taking this medication in combination with other pressor agents (e.g., midodrine, pyridostigmine). Two patients subsequently stopped taking ergotamine/caffeine, one due to side effects (feeling tense) and the other because the medication was not readily available. A previous study also reported nausea and tachyphylaxis with chronic administration in autonomic failure (Dewey et al., 1998). Importantly, ergotamine can produce vascular complications such as arterial vasospasm (ergotism) and valvular heart disease. There was no evidence of vascular complications with chronic ergotamine/caffeine in autonomic failure (Dewey et al., 1998), even at doses reported to cause ergotism in migraine patients (Bigal and Tepper, 2003). There is limited data, however, on long-term safety and efficacy for treatment of orthostatic hypotension. Thus, this drug is recommended only in carefully selected patients without evidence of coronary or peripheral artery disease.

At least half of autonomic failure patients also have paradoxic supine hypertension (Biaggioni and Robertson, 2002). The ideal pressor agent in these patients would prevent the fall in blood pressure with standing, without increasing supine or seated blood pressure. There have been no drugs to date, however, that have met this criteria. Initial studies showed that ergotamine preferentially increases standing blood pressure in patients with orthostatic hypotension (Jennings et al., 1979; Olver et al., 1980), but this has not been a consistent finding with reports of limiting supine hypertension (Chobanian et al., 1983; Dewey et al., 1998). We did not measure supine blood pressure in this study for safety reasons, but similar to other short-acting pressor agents, the use of ergotamine/caffeine should be limited to morning and early afternoon with avoidance of the supine position for at least $4 \mathrm{~h}$ after each dose, following recent standard of care guidelines (Shibao et al., 2013b).

There are some potential limitations to this study. First, autonomic failure patients were enrolled at a tertiary care center for autonomic disorders and may not reflect the broader and less severe disease population. Second, this study included a relatively small number of patients, but was similar in sample size to previous studies of pressor agents in autonomic failure. This study was powered to detect an increase in seated SBP, the primary outcome; however, secondary outcomes including orthostatic tolerance may have reached significance with additional patients. Third, we were not able to evaluate standing blood pressure as our primary endpoint, as most patients are only able to stand for a few seconds to minutes due to disabling presyncopal symptoms. The seated position provides a well-tolerated postural stress in these patients that allows for evaluation over prolonged time periods, and in most patients we have found that the acute seated pressor response is a reasonable predictor of long-term symptomatic efficacy.

\section{AUTHOR CONTRIBUTIONS}

All authors have given final approval of this version of this manuscript, and have agreed to be accountable for all aspects of this work. The following additional author contributions are acknowledged: study conception and design (Luis E. Okamoto, Alfredo Gamboa, André Diedrich, Satish R. Raj, David Robertson, Italo Biaggioni, and Cyndya A. Shibao), acquisition, analysis or interpretation of data (all authors), drafting of the manuscript (Amy C. Arnold and Cyndya A. Shibao), critical revision of the manuscript for intellectual content (Claudia E. Ramirez, Luis E. Okamoto, Alfredo Gamboa, André Diedrich, Satish R. Raj, David Robertson, Italo Biaggioni, and Leena Choi), obtaining funding (David Robertson and Italo Biaggioni), study supervision (David Robertson, Italo Biaggioni, and Cyndya A. Shibao) and statistical analysis (Leena Choi).

\section{ACKNOWLEDGMENTS}

We would like to thank our patients and the staff of the Elliot V. Newman Clinical Research Center at Vanderbilt University. This study was supported by NIH grants P01HL056693, U54NS065736, and UL1RR024975. 


\section{REFERENCES}

Arnold, A. C., and Shibao, C. (2013). Current concepts in orthostatic hypotension management. Curr. Hypertens. Rep. 15, 304-312. doi: 10.1007/s11906-0130362-3

Benowitz, N. L., Byrd, R., Schambelan, M., Rosenberg, J., and Roizen, M. F. (1980). Dihydroergotamine treatment for orthostatic hypotension from Vacor rodenticide. Ann. Intern. Med. 92, 387-388. doi: 10.7326/0003-4819-92-3-387

Bevegard, S., Castenfors, J., and Lindblad, L. E. (1974). Haemodynamic effects of dihydroergotamine in patients with postural hypotension. Acta Med. Scand. 196, 473-477. doi: 10.1111/j.0954-6820.1974.tb01044.x

Biaggioni, I., and Robertson, R. M. (2002). Hypertension in orthostatic hypotension and autonomic dysfunction. Cardiol. Clin. 20, 291-301. doi: 10.1016/S0733-8651(01)00005-4

Biaggioni, I., Zygmunt, D., Haile, V., and Robertson, D. (1990). Pressor effect of inhaled ergotamine in orthostatic hypotension. Am. J. Cardiol. 65, 89-92. doi: 10.1016/0002-9149(90)90031-U

Bigal, M. E., and Tepper, S. J. (2003). Ergotamine and dihydroergotamine: a review. Curr. Pain Headache Rep. 7, 55-62. doi: 10.1007/s11916-003-0011-7

Chobanian, A. V., Tifft, C. P., Faxon, D. P., Creager, M. A., and Sackel, H. (1983). Treatment of chronic orthostatic hypotension with ergotamine. Circulation 67, 602-609. doi: 10.1161/01.CIR.67.3.602

Dewey, R. B., Rao, S. D., Holmburg, S. L., and Victor, R. G. (1998). Ergotamine/caffeine treatment of orthostatic hypotension in parkinsonism with autonomic failure. Eur. J. Neurol. 5, 593-599. doi: 10.1046/j.14681331.1998.560593.x

Dhruva, S. S., and Redberg, R. F. (2010). Accelerated approval and possible withdrawal of midodrine. JAMA 304, 2172-2173. doi: 10.1001/jama.2010.1695

Diedrich, A., and Biaggioni, I. (2004). Segmental orthostatic fluid shifts. Clin. Auton. Res. 14, 146-147. doi: 10.1007/s10286-004-0188-9

Dupont, W. D., and Plummer, W. D. (1990). Power and sample size calculations. A review and computer program. Control Clin. Trials 11, 116-128. doi: 10.1016/0197-2456(90)90005-M

Fouad, F. M., Tarazi, R. C., and Bravo, E. L. (1981). Dihydroergotamine in idiopathic orthostatic hypotension: short-term intramuscular and long-term oral therapy. Clin. Pharmacol. Ther. 30, 782-789. doi: 10.1038/clpt.1981.238

Fouad-Tarazi, F. M., Okabe, M., and Goren, H. (1995). Alpha sympathomimetic treatment of autonomic insufficiency with orthostatic hypotension. Am. J. Med. 99, 604-610. doi: 10.1016/S0002-9343(99)80246-0

Freeman, R., Wieling, W., Axelrod, F. B., Benditt, D. G., Benarroch, E., Biaggioni, I., et al. (2011). Consensus statement on the definition of orthostatic hypotension, neurally mediated syncope and the postural tachycardia syndrome. Auton. Neurosci. 161, 46-48. doi: 10.1016/j.autneu.2011.02.004

Goldstein, D. S., Eisenhofer, G., Stull, R., Folio, C. J., Keiser, H. R., and Kopin, I. J. (1988). Plasma dihydroxyphenylglycol and the intraneuronal disposition of norepinephrine in humans. J. Clin. Invest. 81, 213-220. doi: 10.1172/JCI113298

Hoeldtke, R. D., Cavanaugh, S. T., Hughes, J. D., and Polansky, M. (1986). Treatment of orthostatic hypotension with dihydroergotamine and caffeine. Ann. Intern. Med. 105, 168-173. doi: 10.7326/0003-4819-105-2-168

Jankovic, J., Gilden, J. L., Hiner, B. C., Kaufmann, H., Brown, D. C., Coghlan, C. H., et al. (1993). Neurogenic orthostatic hypotension: a double-blind, placebocontrolled study with midodrine. Am. J. Med. 95, 38-48. doi: 10.1016/00029343(93)90230-M

Jennings, G., Esler, M., and Holmes, R. (1979). Treatment of orthostatic hypotension with dihydroergotamine. Br. Med. J. 2:307. doi: 10.1136/bmj.2.6185.307

Jordan, J., Shannon, J. R., Biaggioni, I., Norman, R., Black, B. K., and Robertson, D. (1998). Contrasting actions of pressor agents in severe autonomic failure. Am. J. Med. 105, 116-124. doi: 10.1016/S0002-9343(98)00193-4

Kaufmann, H., Brannan, T., Krakoff, L., Yahr, M. D., and Mandeli, J. (1988). Treatment of orthostatic hypotension due to autonomic failure with a peripheral alpha-adrenergic agonist (midodrine). Neurology 38, 951-956. doi: 10.1212/WNL.38.6.951

Kaufmann, H., Malamut, R., Norcliffe-Kaufmann, L., Rosa, K., and Freeman, R. (2012). The Orthostatic Hypotension Questionnaire (OHQ): validation of a novel symptom assessment scale. Clin. Auton. Res. 22, 79-90. doi: 10.1007/s10286-011-0146-2

Low, P. A. (2003). Testing the autonomic nervous system. Semin. Neurol. 23, 407-421. doi: 10.1055/s-2004-817725
Low, P. A., Gilden, J. L., Freeman, R., Sheng, K. N., and McElligott, M. A. (1997). Efficacy of midodrine vs placebo in neurogenic orthostatic hypotension. A randomized, double-blind multicenter study. Midodrine Study Group. JAMA 277, 1046-1051. doi: 10.1001/jama.1997.03540370036033

Okamoto, L. E., Shibao, C., Gamboa, A., Choi, L., Diedrich, A., Raj, S. R., et al. (2012). Synergistic effect of norepinephrine transporter blockade and alpha-2 antagonism on blood pressure in autonomic failure. Hypertension 59, 650-656. doi: 10.1161/HYPERTENSIONAHA.111.184812

Olver, I. N., Jennings, G. L., Bobik, A., and Esler, M. (1980). Low bioavailability as a cause of apparent failure of dihydroergotamine in orthostatic hypotension. $\mathrm{Br}$. Med. J. 281, 275-276. doi: 10.1136/bmj.281.6235.275-a

Onrot, J., Goldberg, M. R., Biaggioni, I., Hollister, A. S., Kingaid, D., and Robertson, D. (1985). Hemodynamic and humoral effects of caffeine in autonomic failure. Therapeutic implications for postprandial hypotension. N. Engl. J. Med. 313, 549-554. doi: 10.1056/NEJM198508293130905

Schirger, A., Sheps, S. G., Thomas, J. E., and Fealey, R. D. (1981). Midodrine. A new agent in the management of idiopathic orthostatic hypotension and Shy-Drager syndrome. Mayo Clin. Proc. 56, 429-433.

Schmidt, R., and Fanchamps, A. (1974). Effect of caffeine on intestinal absorption of ergotamine in man. Eur. J. Clin. Pharmacol. 7, 213-216. doi: 10.1007/BF00560383

Shibao, C., Grijalva, C. G., Lipsitz, L. A., Biaggioni, I., and Griffin, M. R. (2013a). Early discontinuation of treatment in patients with orthostatic hypotension. Auton. Neurosci. 177, 291-296. doi: 10.1016/j.autneu.2013.08.064

Shibao, C., Lipsitz, L. A., and Biaggioni, I. (2013b). ASH position paper: evaluation and treatment of orthostatic hypotension. J. Clin. Hypertens (Greenwich) 15, 147-153. doi: $10.1111 /$ jch. 12062

Shibao, C., Okamoto, L., and Biaggioni, I. (2012). Pharmacotherapy of autonomic failure. Pharmacol. Ther. 134, 279-286. doi: 10.1016/j.pharmthera.2011.05.009

Shibao, C., Okamoto, L. E., Gamboa, A., Yu, C., Diedrich, A., Raj, S. R., et al. (2010). Comparative efficacy of yohimbine against pyridostigmine for the treatment of orthostatic hypotension in autonomic failure. Hypertension 56, 847-851. doi: 10.1161/HYPERTENSIONAHA.110.154898

Silberstein, S. D., and McCrory, D. C. (2003). Ergotamine and dihydroergotamine: history, pharmacology, and efficacy. Headache 43, 144-166. doi: 10.1046/j.15264610.2003.03034.x

Smith, J. J., Porth, C. M., and Erickson, M. (1994). Hemodynamic response to the upright posture. J. Clin. Pharmacol. 34, 375-386. doi: 10.1002/j.15524604.1994.tb04977.x

Wright, R. A., Kaufmann, H. C., Perera, R., Opfer-Gehrking, T. L., McElligott, M. A., Sheng, K. N., et al. (1998). A double-blind, dose-response study of midodrine in neurogenic orthostatic hypotension. Neurology 5, 120-124. doi: 10.1212/WNL.51.1.120

Conflict of Interest Statement: Amy C. Arnold was supported by American Heart Association grant 11POST7330010. Claudia E. Ramirez reports no disclosures. Leena Choi reports no disclosures. Luis E. Okamoto reports no disclosures. Alfredo Gamboa is supported by NIH grant K23HL95905. André Diedrich reports no disclosures. Italo Biaggioni is a consultant for Chelsea Therapeutics and Astra Zeneca, is funded by NIH grants P01 HL056693 and U54NS065736, and receives research support from Astra Zeneca and Forest Laboratories. David Robertson is a consultant for Chelsea Therapeutics, and is funded by NIH grants P01HL056693.

Received: 28 April 2014; accepted: 30 June 2014; published online: 24 July 2014.

Citation: Arnold AC, Ramirez CE, Choi L, Okamoto LE, Gamboa A, Diedrich A, Raj $S R$, Robertson D, Biaggioni I and Shibao CA (2014) Combination ergotamine and caffeine improves seated blood pressure and presyncopal symptoms in autonomic failure. Front. Physiol. 5:270. doi: 10.3389/fphys.2014.00270

This article was submitted to Integrative Physiology, a section of the journal Frontiers in Physiology.

Copyright (c) 2014 Arnold, Ramirez, Choi, Okamoto, Gamboa, Diedrich, Raj, Robertson, Biaggioni and Shibao. This is an open-access article distributed under the terms of the Creative Commons Attribution License (CC BY). The use, distribution or reproduction in other forums is permitted, provided the original author(s) or licensor are credited and that the original publication in this journal is cited, in accordance with accepted academic practice. No use, distribution or reproduction is permitted which does not comply with these terms. 